\title{
Cell-Based High-Throughput Screening Assay Identifies 2',2'- Difluoro-2' -deoxycytidine Gemcitabine as a Potential Antipoliovirus Agent
}

\author{
Zhuoran Zhang ${ }^{\dagger, \|}$, Enzhuo Yang ${ }^{\dagger, \S, \|}$, Chunmiao Hu ${ }^{\dagger, \|}$, Han Cheng ${ }^{\dagger}$, Crystal Y. Chen ${ }^{\dagger}$, Dan \\ Huang $^{\dagger}$, Richard Wang ${ }^{\dagger}$, Yue Zhao ${ }^{\dagger}$, Lijun Rong ${ }^{\dagger}$, Marco Vignuzzi ${ }^{\ddagger}$, Hongbo Shen ${ }^{\star}, \S$, Ling \\ Shen ${ }^{*},+$, and Zheng W. Chen ${ }^{*} \dagger, \perp$ \\ tDepartment of Microbiology and Immunology and Center for Primate Biomedical Research, \\ University of Illinois College of Medicine, 909 South Wolcott Avenue, E704, M/C790, Chicago, \\ Illinois 60612, United States \\ §Unit of anti-tuberculosis immunity, CAS Key Laboratory of Molecular Virology and Immunology, \\ Institut Pasteur of Shanghai, Chinese Academy of Sciences, Shanghai 200031, China \\ ${ }^{\perp}$ Institut Pasteur of Shanghai, Shanghai 200031, China \\ ҒViral Populations and Pathogenesis Unit, CNRS UMR 3569, Institut Pasteur, 25-28 rue du Dr. \\ Roux, 75724 Paris cedex 15, France
}

\section{Abstract}

As we approach the global eradication of circulating wild-type polioviruses (PV), vaccination with oral poliovirus vaccine (OPV) has led to the emergence of circulating vaccine-derived poliovirus (cVDPV) and vaccine-associated paralytic poliomyelitis (VAPP). Complete cessation of all poliovirus infections may require stopping use of OPV and formulating improved vaccines and new antiviral drugs. Currently, no licensed drugs are available to treat chronically infected poliovirus excretors. Here, we created a modified PV expressing Gaussia Luciferase (Sb-Gluc) and developed a cell-based high-throughput screening (HTS) antiviral assay. Using the validated HTS assay, we screened the FDA-approved drug library of compounds and identified candidate agents capable of inhibiting PV replication. We then characterized antipoliovirus activity for the best hit, gemcitabine, a nucleoside analogue used in tumor chemotherapy. We found that gemcitabine inhibited PV Mahoney replication with an $\mathrm{IC}_{50}$ of $0.3 \mu \mathrm{M}$. It completely protected HeLa cells from PV-induced cytopathic effects at $25 \mu \mathrm{M}$, without detectable toxicity for cell viability. Furthermore, a gemcitabine metabolite directly inhibited the ability of PV RNA polymerase to synthesize or elongate PV RNA. Because PV RNA polymerase is somehow conserved among

\footnotetext{
*Corresponding Authors: (H.S.) hbshen@ips.ac.cn.; (L.S.) 1shen@uic.edu.; (Z.W.C.) zchen@uic.edu. "Z.Z., E.Y., and C.H. contributed equally.

Supporting Information

The Supporting Information is available free of charge on the ACS Publications website at DOI: 10.1021/acsinfecdis.6b00116.

Additional figures showing the inhibitory effects of gemcitabine against PV replication and a table describing other nucleoside analogues screened in the HTS assay (PDF)

Notes

The authors declare no competing financial interest.

L.S. and Z.W.C. share senior authorship.
} 
species in the Picornaviridae family, gemcitabine may be further developed as an attractive broadspectrum antiviral for PV and others.

\section{Graphical abstract}

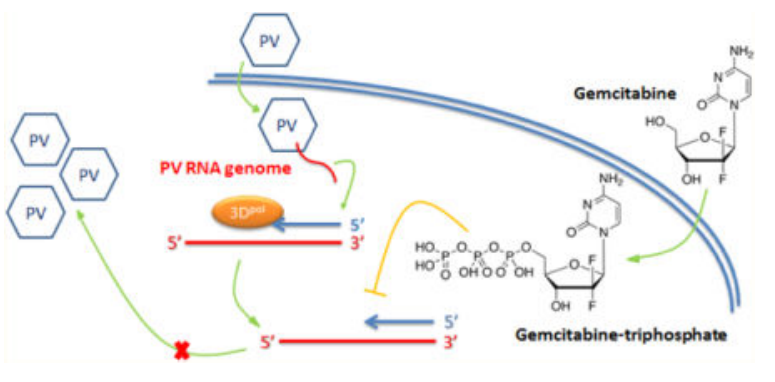

\section{Keywords}

poliovirus; antiviral; gemcitabine; RNA-dependent RNA polymerase inhibitor

We are approaching the global eradication of circulating wild-type polioviruses, but that end point is fraught with obstacles and remains uncertain. ${ }^{1}$ Importantly, oral poliovirus vaccine (OPV) immunization of certain subpopulations including immune-compromised persons can lead to the continuous shedding and secretion of viruses in feces and to the emergence of circulating vaccine-derived poliovirus (cVDPV) and vaccine-associated paralytic poliomyelitis (VAPP) or even outbreaks of poliomyelitis in some tropical regions. ${ }^{1-,, 5}$ In fact, 52 of the 359 polio cases in 2014 were reported to result from cVDPV. ${ }^{1}$ Complete cessation of all poliovirus infections requires stopping the use of OPV and developing an improved vaccine and effective antiviral drugs to treat chronically infected poliovirus excretors (http://www.polioeradication.org/Resourcelibrary/Strategyandwork.aspx). It is presumed that PV antivirals can significantly benefit poliovirus eradication and maintain the polio-free world. ${ }^{6,7}$ However, there are no licensed antiviral drugs available to treat chronically infected poliovirus excretors.

Ideally, two antivirals with different mechanisms of action are necessary for the end game and to prevent potential polio outbreaks post eradication. ${ }^{8}$ Three pipeline candidate drugs targeting PV capsid protein, Pleconaril (WIN63843) ${ }^{9}$ (https://clinicaltrials.gov/show/ NCT00031512), Pocapavir (V-073) ${ }^{10,11}$ (http://adisinsight.springer.com/drugs/800007750), and Vapendavir (BTA-798) ${ }^{12}$ (http://investors.aviragentherapeutics.com/releasedetail.cfm? releaseid=899451), were evaluated in phase II clinical trials, but no clinical study report or future development plan has been released. Although Ribavirin, ${ }^{13,14}$ Amiloride, ${ }^{15}$ and compound GPC-N1 $14^{16}$ were shown to have detectable antiviral activities by action on PV RNA polymerase, these antiviral agents have not moved on to clinical trials. Thus, there is rationale to continue to identify and characterize new antipolioviral agents for ultimate development of therapeutic drugs against PV infections. ${ }^{17}$

In this study, we created a modified PV expressing Gaussia Luciferase (Sb-Gluc) and developed a cell-based high-throughput screening (HTS) antiviral assay. To shorten the time from bench to bed, we employed our HTS assay to screen the FDA-approved drug library of 
compounds for repurposing. The validated HTS system identified candidate agents capable of inhibiting PV replication. We then characterized anti-poliovirus activity for the best hit, gemcitabine, which is a nucleoside analogue used in tumor chemotherapy. We found that gemcitabine inhibited PV Mahoney replication with an $\mathrm{IC}_{50}$ of $0.3 \mu \mathrm{M}$. It completely protected HeLa cells from PV-induced cytopathic effects at the concentration of $25 \mu \mathrm{M}$, without detectable toxicity for cell viability. Furthermore, a gemcitabine metabolite directly inhibited the ability of PV RNA-dependent RNA polymerase (RdRp) 3Dpol to synthesize or elongate PV RNA. Our data suggest that gemcitabine could be further developed as a prospective PV antiviral.

\section{RESULTS}

\section{Generation of Recombinant Poliovirus Producing Gaussia Luciferase (Sb-Gluc)}

Gaussia Luciferase (GLuc) reporter gene was introduced into the genome of the attenuated poliovirus vaccine Sabin strain to generate an Sb-Gluc construct (Figure 1a). The 558 bp GLuc was inserted at the 3 '-terminal of the poliovirus VP1 by overlap extension PCR cloning strategy. ${ }^{18}$ Given that there is a natural poliovirus $2 \mathrm{~A}$ protease recognition site at the end of VP1, an additional 2A protease recognition site was added in front of the GLuc reporter gene. As a result, the Gaussia Luciferase (GLuc) protein was cut by the viral 2A protease and released from the viral polyprotein after translation.

To examine the characteristics of the Sb-Gluc replicon, HeLa cells were infected by either Sb-Gluc, wild type Sabin strain (Supporting Information Figure S1), or wild type PV Mahoney (WT-PV). Sb-Gluc generated plaques on HeLa cells 2 days after incubation, although the plaques were smaller than those generated by WT-PV (Figure 1b). Whereas SbGluc replicated with kinetics similar to those of WT-PV up to $72 \mathrm{~h}$ post infection, the titers were significantly lower: the Mahoney strain generated $>10^{7} \mathrm{PFU} / \mathrm{mL}$ after $72 \mathrm{~h}$ of incubation, whereas Sb-Gluc achieved $>10^{6} \mathrm{PFU} / \mathrm{mL}$ (Figure 1c). Indeed, it is well-known that Sabin 1 strain replicates with titers 1 order of magnitude below the wild type Mahoney strain. ${ }^{19}$ qRT-PCR assay also revealed a continuous increase of both Sb-GLu and WT-PV viral RNA copy numbers up to $72 \mathrm{~h}$ post infection (Figure 1d). Together, these results indicate that the Sb-Gluc replicon is able to replicate robustly and induce cytopathic effects on HeLa cells up to $72 \mathrm{~h}$ post infection.

GLuc was produced along with the replication of Sb-Gluc and accumulated in the cytoplasm. After incubation, cells were lysed to release GLuc into culture medium. Heating at $65{ }^{\circ} \mathrm{C}$ for 20 min completely inactivated Sb-Gluc virus while inducing no effect on the activity of GLuc (data not shown). Consistent with the plaque assay and qRT-PCR results, a luminescent signal was observed in the Sb-Gluc samples and increased throughout the period of incubation (Figure 1e). Guanidine hydrochloride ( $\mathrm{GnHCl} ; 2 \mathrm{mM}$ ) served as control as it could inhibit poliovirus replication by interfering with viral $2 \mathrm{C}$ protein. ${ }^{20}$ The luminescence signal did not increase when $2 \mathrm{mM} \mathrm{GnHCl}$ was present in the culture medium (Figure 1e), indicating that the GLuc production was inhibited when viral replication was blocked. In summary, the expression of GLuc was validated as a surrogate for replication of Sb-Gluc virus in HeLa cells. 


\section{Validation and Optimization of a Cell-Based High-Throughput Screening Antipolioviral Assay}

We then utilized the Sb-Gluc virus to develop a cell-based HTS assay. We hypothesized that compounds capable of inhibiting Sb-Gluc replication can be identified by reduced luminescent signals compared to the blank controls.

To validate the application of Sb-Gluc on HTS assay, a pilot experiment was conducted using 96-well plates. The undiluted viral solution $\left(10^{6} \mathrm{PFU} / \mathrm{mL}\right)$, as well as the 5, 25, or 125 times diluted viral stock, was used to infect HeLa cells. As a control for background noise, we measured residual luminescence in the viral stocks, which may have been carried over during production of the Sb-Gluc virus.

After $24 \mathrm{~h}$ of incubation, an increase in the luminescent signals was observed in all of the groups except the $2 \mathrm{mM} \mathrm{GnHCl}$ treated group and the background controls (Figure 2a). The samples infected by 5 -fold diluted viral solution gave the highest luminescent signal of $>2 \times$ $10^{6}$ units after $24 \mathrm{~h}$ of incubation (Figure 2a, left). At $48 \mathrm{~h}$ after infection, samples infected with 25 -fold diluted viral solution gave the highest luminescence signal of $\sim 5 \times 10^{6}$ units (Figure 2a, right). A 6-fold increase of luminescent signal was also observed in samples infected with 125 -fold diluted viral solution during the second $24 \mathrm{~h}$ of incubation. However, the luminescent signal remained unchanged in the undiluted group and only slightly increased in the 5 -fold diluted samples during the second $24 \mathrm{~h}$ of incubation (Figure 2a). One possible explanation is that although a higher titer of Sb-Gluc led to a rapid start in viral replication and GLuc expression, most of the cells were immediately killed, which limited the amount of GLuc generated. In the case of infection using a lower titer of Sb-Gluc, the virus continued to replicate and spread to the rest of the cells so that more GLuc was generated through multiple cycles of infection.

For the samples infected with undiluted viral solution, preexisting GLuc contributed to almost half of the total signal (Figure 2b). The background was significantly reduced when viral solution was extensively diluted. The background was $<10 \%$ in the samples infected by 25 - or 125 -fold diluted viral solutions after $24 \mathrm{~h}$ of incubation and $<1 \%$ after $48 \mathrm{~h}$ of incubation (Figure $2 \mathrm{~b})$. Therefore, 100 -fold diluted viral solution $\left(10^{4} \mathrm{PFU} / \mathrm{ml}\right)$ was used in the HTS assay.

The $Z$-factor of this assay was calculated as 0.877 by three positive and negative controls. Collectively, the results suggest that the cell-based HTS assay is robust and reliable.

\section{Identification of Prospective Antipoliovirus Agents Including Gemcitabine Using the Cell- Based HTS Assay}

The Prestwick Compound Library containing >1000 compounds of FDA-approved drugs was used for the initial screening, and $2 \mathrm{mM} \mathrm{GnHCl}$ was included as positive control. The inhibitory effect of each compound against poliovirus replication was reflected by $E_{\mathrm{c}}$, which was calculated as follows: $E_{\mathrm{c}}=1-L_{\mathrm{c}} / \mu_{\mathrm{n}} \times 100 \%$, where $\mu_{\mathrm{n}}$ is the mean of negative controls with Sb-Gluc only and $L_{\mathrm{c}}$ is the read of luminescence signal for the specific compound. For example, the $E_{\mathrm{c}}$ of $\mathrm{GnHCl}$ is $98 \%$, which means $\mathrm{GnHCl}$ inhibits $98 \%$ of viral replication compared to the untreated control. $V_{\mathrm{c}}$ was used to reflect the viability of cells after 
incubation in the presence of each compound, which was calculated as follows: $V_{\mathrm{c}}=L_{\mathrm{c}} / \mu_{\mathrm{p}} \times$ $100 \%$, where $\mu_{\mathrm{p}}$ is the mean of positive controls with HeLa only without any compound treatment and $L_{\mathrm{c}}$ is the read of luminescence signal for specific compound. The $V_{\mathrm{c}}$ of $2 \mathrm{mM}$ $\mathrm{GnHCl}$ is $95 \%$, which means $95 \%$ of the cells remain alive after $48 \mathrm{~h}$ of incubation (data not shown).

The qualified compound should achieve $>80 \% E_{\mathrm{c}}$ and $>70 \% V_{\mathrm{c}}$. Eleven compounds were identified following this criterion (Table 1). Among these, itraconazole and gemcitabine were the best hits conferring $E_{\mathrm{c}}$ values of 96.0 and $96.6 \%$, respectively. Itraconazole's $V_{\mathrm{c}}$ was $79.4 \%$, whereas gemcitabine's $V_{\mathrm{c}}$ was $87.9 \%$. Another compound, ketoconazole, similar to itraconazole, was also identified with an $E_{\mathrm{c}}$ of $83.0 \%$ and a $V_{\mathrm{c}}$ of $103.1 \%$.

Becuase gemcitabine was reported as a nucleoside analogue of cytidine and extensively used in cancer chemotherapy, ${ }^{21,22}$ we comparatively evaluated gemcitabine and other forms of published nucleoside analogues including antitumor drugs and HIV antivirals. The results demonstrated that only gemcitabine, but not other forms of nucleoside analogues, could achieve remarkable inhibition of poliovirus replication (Supporting Information Table S1).

Collectively, our validated cell-based HTS antiviral assay allowed us to identify prospective antipoliovirus agents including gemcitabine.

\section{Characterization of Gemcitabine and Other Antipoliovirus Agents for the Ability To Inhibit PV Replication}

We then sought to verify and characterize gemcitabine, itraconazole, and ketoconazole for their antiviral effects on WT-PV using plaque assays. All of the HeLa cells were killed within $48 \mathrm{~h}$ of incubation without treatment (Supporting Information Figure S2). A partial protective effect of $25 \mu \mathrm{M}$ itraconazole and ketoconazole was confirmed on HeLa cells (Supporting Information Figure S2). In contrast, $25 \mu \mathrm{M}$ gemcitabine completely protected HeLa cells from WT-PV-mediated damages, without a single plaque being observed (Figure 3a). Because gemcitabine conferred the best inhibitory effect against WT-PV, we focused on the following verification experiments.

First, Sb-Gluc was used to explore the inhibitory characteristics of gemcitabine against poliovirus. $\mathrm{IC}_{50}$ was calculated as $2.6 \mu \mathrm{M}$ on the basis of luminescent signal (Figure $3 \mathrm{~b}$ ). qRT-PCR detecting Sb-Gluc RNA copies gave rise to similar results and revealed $\mathrm{IC}_{50}$ as 1 $\mu \mathrm{M}$ (Figure 3c). Concurrently, gemcitabine did not affect cell viability at concentrations of up to $100 \mu \mathrm{M}$ as indicated by intracellular ATP levels (Figure 3d). Gemcitabine also inhibited Sb-GLuc replication in 293T cells without cytotoxic effect up to $100 \mu \mathrm{M}$ (Supporting Information Figure S3). However, Vero cells are sensitive to gemcitabine, and $0.1 \mu \mathrm{M}$ gemcitabine treatment kills Vero cells. The death of host cells brings down Sb-GLuc signals in the infected Vero cells as well (Supporting Information Figure S3). These results further support that gemcitabine's antiviral effects observed in HeLa and 293T cells are specific and not due to impact on host cells' viabilities.

Second, WT-PV was used to further evaluate gemcitabine's antiviral effect. A single dose of $25 \mu \mathrm{M}$ gemcitabine introduced at the beginning of the incubation was able to reduce up to 
99\% of PFU as well as viral RNA copies at the first $24 \mathrm{~h}$ of incubation, although only $60 \%$ reduction was observed at $48 \mathrm{~h}$ post infection (Supporting Information Figure S4). It is possible that gemcitabine was exhausted after $24 \mathrm{~h}$ of incubation, which led to a loss of antiviral effect. To test this, gemcitabine was added every $24 \mathrm{~h}$ during the incubation. No noticeable increase in the viral RNA copies was observed in the samples that were treated by $25 \mu \mathrm{M}$ gemcitabine every $24 \mathrm{~h}$ (Figure $3 \mathrm{e}$ ). $\mathrm{IC}_{50}$ was determined as $0.3 \mu \mathrm{M}$ by measuring the RNA copy numbers, and dosages $>2 \mu \mathrm{M}$ conferred $>90 \%$ inhibition on WT-PV replication (Figure 3f). Similar results were obtained from plaque assays (Supporting Information Figure S5).

Thus, although gemcitabine exerts an antiviral effect on both Sb-Gluc and wild type poliovirus Mahoney, the compound doses of up to $100 \mu \mathrm{M}$ do not affect cell viability as reflected by the intracellular ATP levels. These results therefore suggest that gemcitabine could be a potential antipoliovirus agent with high efficiency and limited toxicity.

\section{Gemcitabine Suppression of PV Replication Was Consistent with the Ability of Its Metabolite dFdC-TP To Inhibit Elongation or Synthesis of PV RNA}

Gemcitabine is extensively used in cancer chemotherapy because it is metabolized as a nucleoside analogue of cytidine. It replaces the hydrogens at $2^{\prime}$-positions by fluorine $\left(2^{\prime}, 2^{\prime}\right.$ difluoro-2' -deoxycytidine, $\mathrm{dFdC}$ ). In the case of cancer chemotherapy, $\mathrm{dFdC}$ is taken up by tumor cells and phosphorylated into its effective metabolite, $\mathrm{dFdC}-\mathrm{TP}$, which can be incorporated into DNA or RNA chains and block chain elongation. ${ }^{21,22}$ We presumed that gemcitabine metabolite interferes with poliovirus RNA elongation and thereby inhibits viral replication. To test this, we took advantage of the cell-free polio RNA synthesis system, in which recombinant PV RNA-dependent RNA polymerase can synthesize double-stranded RNA (dsRNA) product based on single-stranded RNA (ssRNA) template. ${ }^{23}$ This cell-free system would allow us to directly test whether the dFdC-TP metabolite derived from gemcitabine could affect poliovirus RNA elongation.

Gemcitabine metabolite dFdC-TP significantly reduced synthesis or elongation of PV dsRNA in a dose-dependent manner (Figure 4a). Specifically, dFdC-TP alone without r-CTP (lane 2, Figure 4a) led to complete inhibition of dsRNA synthesis or elongation, which was identical to that of the negative control (lane 1). The up-shifted patterns of dsRNA on the gel suggested apparent inhibition of dsRNA elongation was observed when dFdC-TP and r-CTP was added in a 1:1 ratio (lane 3, Figure 4a), and weak inhibition was found when dFdC-TP and r-CTP were added in a 1:10 ratio (10-fold reduction of dFdC-TP, lane 4, Figure 4a). In addition to the shift of the bands, the amount of RNA also increased in a dose-dependent manner, which indicates dFdC-TP prevents nucleotides from being incorporated (Figure 4b).

The dose-dependent inhibition of dsRNA elongation supports our hypothesis that gemcitabine suppression of PV replication consists of the ability of its metabolite to inhibit poliovirus RNA elongation. This is also consistent with the observations that $2^{\prime}$-modified nucleotides destabilize the polymerase-RNA complex and lead to abortive replication products. $^{24,25}$ 


\section{DISCUSSION}

In the current study, we created a modified PV expressing Gaussia Luciferase (Sb-Gluc) and developed a cell-based HTS antiviral assay. The validated HTS assay allowed us to identify the best hit, gemcitabine, as a potent anti-PV agent candidate. Whereas gemcitabine inhibited PV Mahoney replication with an $\mathrm{IC}_{50}$ of $0.3 \mu \mathrm{M}$, it completely protected $\mathrm{HeLa}$ cells from PV-induced cytopathic effects at $25 \mu \mathrm{M}$, without detectable toxicity for cell viability. Furthermore, a gemcitabine metabolite directly inhibited the ability of PV RNA polymerase to synthesize or elongate PV RNA. Our findings are consistent with the current efforts to develop therapeutic drugs for the treatment of chronically infected poliovirus excretors.

Our cell-based HTS assay appears to be robust and reliable, with a $Z$-factor of 0.877 . The modified viral replicon containing 558 bp GLuc reporter gene is a useful tool for both HTS assay and evaluation of viral replication, as it is able to replicate and induce plaques in host cells in a pattern similar to the wild type PV. GLuc generates strong luminescent signals up to $72 \mathrm{~h}$ along with the viral replication (Figure 1). Our cell-based HTS system is also of merit in that it can identify compounds targeting various steps of the viral life cycle, including viral entry, replication, release, etc. In addition, the cell-based HTS assay can also reveal host factors involved in the viral life cycle. For example, itraconazole, one of the compounds we identified, was also shown by another group to inhibit enterovirus replication by blocking oxysterol-binding protein (OSBP) mediated cholesterol transportation between endoplasmic reticulum (ER) and Golgi. ${ }^{26,27}$

The identification of gemcitabine as the best hit in our cell-based HTS leads to the subsequent definition of antipoliovirus function. Gemcitabine at $25 \mu \mathrm{M}$ completely protects HeLa cells from the PV infection and inhibits viral RNA replication up to $90 \mathrm{~h}$ post infection. With an $\mathrm{IC}_{50}$ of $0.3 \mu \mathrm{M}$, gemcitabine exhibited limited cytotoxicity to HeLa cells at concentrations up to $100 \mu \mathrm{M}$. Although gemcitabine was also reported to inhibit influenza A virus replication in vitro, ${ }^{28}$ its mechanism of action was not elucidated. In contrast, gemcitabine suppression of PV replication is consistent with the ability of its metabolite dFdC-TP to inhibit PV dsRNA elongation or synthesis. Our cell-free system using recombinant RdRp and ssRNA template clearly shows a dose-dependent inhibition of RNA elongation when dFdC-TP is present. This result suggests that gemcitabine's antiviral effect is at least partially achieved by inhibition of viral RNA elongation.

The inhibition of PV RNA synthesis by the gemcitabine metabolite is also in line with reports in cancer research indicating that gemcitabine acts as a cytidine analogue, which is extensively used in chemotherapies for various cancers. ${ }^{21,22}$ On the basis of the structural studies of the interaction between enteroviruses RdRp and $2^{\prime}$-modified NTPs, the ribose $2^{\prime}$ hydroxyl group is likely to trigger catalysis by the viral polymerase, which plays important roles in blocking viral RNA elongation. ${ }^{24,25}$ Notably, we evaluated other forms of nucleoside analogues including antitumor drugs and HIV antivirals together with gemcitabine. None of those known nucleoside analogues achieved such a remarkable inhibition of poliovirus replication as did gemcitabine. Even the well-known nucleoside analogue ribavin, capable of inhibiting PV replication by increasing the mutation rate of the 
RdRp, ${ }^{13,14}$ could only reduce $60.3 \%$ of viral replication, whereas gemcitabine readily achieved $96.6 \%$ reduction. Moreover, although most of the compounds showed limited cytotoxicity, some nucleoside analogues were found to be toxic to the HeLa cells. For example, azaguanine-8 reduced the intracellular ATP level to $47.54 \%$, whereas gemcitabine had almost no cytotoxic effect on HeLa cells at concentrations of up to $100 \mu \mathrm{M}$.

The appreciable anti-PV potency and low cytotoxicity of gemcitabine support further studies to evaluate gemcitabine for therapeutic effects on PV infection in a recently developed nonhuman primate model of oral poliovirus infection leading to paralytic poliomyelitis. ${ }^{29}$ Pilot PK studies of gemcitabine in rhesus macaques demonstrated subtle and reversible impact on immune cell counts and liver/kidney functions (Supporting Information Figure S7). The utility of gemcitabine antiviral is also supported by a recent observation that gemcitabine and ribavirin could mediate synergistic inhibition of coxsackievirus B3 and enterovirus $71 .{ }^{30}$ Because PV RNA-dependent RNA polymerase (RdRp) is conserved among members in the Picornaviridae family ${ }^{31,32}$ and it is known that PV is much less sensitive to $2^{\prime}$ modifications than coxsackievirus $B 3,{ }^{33}$ gemcitabine could potentially serve as a lead compound of broad-spectrum antiviral against PV and other picornavirus species.

\section{MATERIALS AND METHODS}

\section{Generation of Poliovirus Construct Expressing Gaussia Luciferase (Sb-Gluc)}

Complete cDNA of poliovirus attenuated vaccine Sabine strain was from Vignuzzi's laboratory at Institut Pasteur. Gaussia Luciferase (GLuc) gene was cloned from pSV40GLuc control plasmid (New England BioLabs). GLuc was inserted into the end of the VP1 region by overlap extension PCR method ${ }^{18}$ using the following primers: $5^{\prime}$ GGATGGTACGCTTACACCCCTCTCCACCAAGGACTTAACGACTTACGGTTTTGGTC ATGGCGGAGGTGG-GGGAGGTGAATTCATGGGAGTCAAAGTTCTGTTTGCCC-3' and $5^{\prime}$ -

CCGCTTTGTTTTGGTGTCCGAATCCATATGTGGTCAGATCCTCGAGGTCACCACCG GCCCCCTT- $3^{\prime}$. The primers contain overlap with both the GLuc gene and the poliovirus cDNA VP1 region. Briefly, the GLuc gene was first cloned by PCR amplification using the described primer pair. The PCR products were purified using gel extraction kit (Qiagen) and used as mega-primer in the second round of PCR amplification to insert the GLuc gene into poliovirus cDNA. The insertion of GLuc was confirmed by PCR extension using primers $5^{\prime}$ CCCGTGGTGACATCT-GAGTA-3' and 5'-CGAGAAATGGGACGACTACAC-3'.

The Sb-Gluc plasmid was passed in Escherichia coli SURE 2 strain (Agilent Technologies) to avoid mutation and deletion in the plasmid. The Sb-Gluc cDNA was in vitro transcribed into RNA using a T7 RiboMAX Express Large Scale RNA Production System (Promega). The RNA product was used to transfect HeLa cells through electroporation. The transfected HeLa cells were incubated in DMEM culture medium with $10 \%$ FBS (Gibco) at $37{ }^{\circ} \mathrm{C}$ with $5 \% \mathrm{CO}_{2}$ for 3 days until complete cytotoxicity was observed. The culture medium was centrifuged to remove the cell fragments, and the supernatant containing Sb-Gluc replicons were collected. The supernatant was concentrated using a 100 filter KD (Millipore) by centrifuging at $4500 \mathrm{rpm}$ for $30 \mathrm{~min}$. The filtered supernatant was diluted by DMEM culture medium containing $10 \% \mathrm{FBS}$ to the final volume of $3 \mathrm{~mL}$ and kept at $-20^{\circ} \mathrm{C}$ as stock vial. 


\section{Cell-Based High-Throughput Screening Assay}

The screening assay was performed on 96- or 384-well plates using an automated workstation (PerkinElmer). The compound library screened is the Prestwick Chemical Library (Prestwick Chemical) For the 96-well plate, $5 \times 10^{4}$ cells were inoculated per well with $100 \mu \mathrm{L}$ of complete culture medium (DMEM culture medium containing 10\% FBS). Cells were incubated overnight at $37{ }^{\circ} \mathrm{C}$ with $5 \% \mathrm{CO}_{2}$ to form a cell monolayer. After incubation, culture medium was removed and replaced by $60 \mu \mathrm{L}$ of fresh complete culture medium containing the designated compound and $40 \mu \mathrm{L}$ of viral solution. For the 384-well plate, $10^{4}$ cells were inoculated per well with $30 \mu \mathrm{L}$ of complete culture medium and incubated overnight at $37{ }^{\circ} \mathrm{C}$ with $5 \% \mathrm{CO}_{2}$. After incubation, culture medium was removed and replaced with $30 \mu \mathrm{L}$ of fresh complete culture medium containing $10 \mu \mathrm{M}$ designated compound using a gridding tool (V\&P Scientific). After that, $10 \mu \mathrm{L}$ of viral solution containing $2 \times 10^{5} \mathrm{PFU}$ Sb-Gluc was added per well and incubated for another 2 days. The plates were kept in $37^{\circ} \mathrm{C}$ with $5 \% \mathrm{CO}_{2}$ for another 2 days. Before the viral replication was tested, viruses were inactivated by heating at $56^{\circ} \mathrm{C}$ for $30 \mathrm{~min}$.

Viral replication was examined by reading the luminescent signals using a BioLux Gaussia Luciferase Assay Kit (New England BioLabs). A duplicate plate not containing virus was conducted to test the cytotoxicity of the compound to the HeLa cells. Cell viability was measured by intracellular ATP level using a CellTiter-Glo Luminescent Cell Viability Assay (Promega). ${ }^{34}$ For the set of plates with Sb-Gluc infection, each compound's inhibitory effect on poliovirus replication $\left(E_{\mathrm{c}}\right)$ was calculated as follows: $E_{\mathrm{c}}=1-L_{\mathrm{c}} / \mu_{\mathrm{n}} \times 100 \%$, where $\mu_{\mathrm{n}}$ is the mean of negative controls with Sb-Gluc only on the specific plate and $L_{\mathrm{c}}$ is the read of luminescence signal for the specific compound. For the set of plates without Sb-Gluc infection, the cell viability rate for each compound on HeLa cells $\left(\mathrm{V}_{\mathrm{c}}\right)$ was calculated as follows: $V_{\mathrm{c}}=L_{\mathrm{c}} / \mu_{\mathrm{p}} \times 100 \%$, where $\mu_{\mathrm{p}}$ is the mean of positive controls with HeLa only without any compound treatment and $L_{\mathrm{c}}$ is the read of luminescence signal for a specific compound.

The $Z$-factor of the HTS assay is calculated as follows:

$$
\text { Z- factor }=1-\frac{3\left(\sigma_{\mathrm{p}}+\sigma_{\mathrm{n}}\right)}{\left|\mu_{\mathrm{p}}-\mu_{\mathrm{p}}\right|}
$$

$\sigma_{\mathrm{p}}$ and $\sigma_{\mathrm{n}}$ are the variances of positive and negative controls, whereas $\mu_{\mathrm{p}}$ and $\mu_{\mathrm{n}}$ are the means of positive and negative controls.

\section{Plaque Assays}

A total of $10^{6} \mathrm{HeLa}$ cells were inoculated to each well on a 12-well plate with $2 \mathrm{~mL}$ of complete culture medium. The plate was kept in $37{ }^{\circ} \mathrm{C}$ with $5 \% \mathrm{CO}_{2}$ overnight to form cell monolayers. $2 \times$ DMEM culture medium and $0.6 \%$ agarose were prepared before the experiment. To prepare $2 \times$ DMEM culture medium, $27 \mathrm{~g}$ of DMEM powder (Sigma) and 2.4 $\mathrm{g}$ of sodium bicarbonate (Thermo Fisher) were dissolved and mixed in $1 \mathrm{~L}$ of sterile water. After that, $40 \mathrm{~mL}$ of FBS (Gibco) and $20 \mathrm{~mL}$ of penicillin/streptomycin (Gibco) were added and filtered by using a $0.22 \mu \mathrm{M}$ filter (Millipore). To prepare $0.6 \%$ agarose, $0.6 \mathrm{~g}$ of 
ultrapure agarose powder (Invitrogen) was dissolved in $100 \mathrm{~mL}$ of sterilized water by heating. $2 \times$ DMEM culture medium was kept in a $37{ }^{\circ} \mathrm{C}$ water bath prior to the experiment, whereas $0.6 \%$ agarose was kept in a $40{ }^{\circ} \mathrm{C}$ water bath. To infect the HeLa cells, the culture medium was removed and the cell monolayers were washed once with PBS (Gibco). Two hundred microliters of viral solution with designated PFU was added to the center of the cell monolayers and incubated at $37{ }^{\circ} \mathrm{C}$ with $5 \% \mathrm{CO}_{2}$ for $10 \mathrm{~min}$ to allow the virus to infect HeLa cells. After incubation, extracellular virus was removed by washing once with PBS. One milliliter of $2 \times$ DMEM culture medium $\left(37^{\circ} \mathrm{C}\right)$ and $1 \mathrm{~mL}$ of $0.6 \%$ agarose $\left(40{ }^{\circ} \mathrm{C}\right)$ were mixed and immediately added to cover the cell monolayers. The plate was incubated at $37{ }^{\circ} \mathrm{C}$ with $5 \% \mathrm{CO}_{2}$ for up to 3 days until cytotoxicity effects were observed. The covers were discarded. The cell monolayers were washed once using PBS and fixed by $2 \%$ formaldehyde at room temperature for $10 \mathrm{~min}$. After fixation, the cell monolayers were washed once using PBS and stained by crystal violet solution (Sigma) for $10 \mathrm{~min}$ at room temperature. After staining, the cell monolayers were carefully washed by water to remove extra staining solution and air-dried to read the plaques.

\section{qRT-PCR}

Viral RNA was extracted using an RNeasy kit (Qiagen) and converted into cDNA using a MEGAscript T7 kit (Thermo Fisher). To perform qRT-PCR, $1 \mu \mathrm{L}$ of cDNA was loaded with $10 \mu \mathrm{L}$ of TaqMan Universal PCR Master kit (Applied Biosystem), $1 \mu \mathrm{L}$ primers pairs $5^{\prime}$ AGGTCAGATGCTTGAAAGC-3' and 5'-TCCACTGGCTTCAGTGTT-3', $1 \mu \mathrm{L}$ of TaqMan MGB probe $5^{\prime}$-CACAGTCCGTGAAACGGTGG-3' (Life Technologies), and $7 \mu \mathrm{L}$ of $\mathrm{ddH}_{2} \mathrm{O}$. The mixture was then loaded onto an Applied Biosystem Standard 7300 Real Time PCR system (Thermo Fisher). The thermal cycle started at $50{ }^{\circ} \mathrm{C}$ for $2 \mathrm{~min}$ followed by $95{ }^{\circ} \mathrm{C}$ for $10 \mathrm{~min}$, then repeated 40 rounds at $95^{\circ} \mathrm{C}$ for $15 \mathrm{~s}$, and finished by $60{ }^{\circ} \mathrm{C}$ for 1 min. Samples containing $10^{6}, 10^{5}, 10^{4}, 10^{3}$, and $10^{2}$ copies of viral RNA were used as standard controls.

\section{In Vitro Elongation Assay}

The in vitro elongation assay was performed as described before. ${ }^{23}$ Briefly, recombined poliovirus RNA-dependent RNA polymerase $3 \mathrm{D}^{\mathrm{pol}}$ and single- stranded RNA template were incubated with normal A/U/G-TP with or without CTP or the triphosphate form of gemcitabine, $2^{\prime}, 2^{\prime}$-difluoro-2' -deoxycytidine triphosphate (dFdC-TP, BOC Science). 3D pol was kindly provided by Dr. Peersen (Colorado State University, Ft. Collins, CO, USA), 35,36 and viral cDNA lacking the VP1 region was kindly provided by Dr. Flanegan (University of Florida, Gainesville, FL, USA). The viral cDNA was digested by restriction enzyme SpeI or AvrI (New England BioLabs) and transcribed into ssRNA in vitro using a T7 RiboMAX Express Large Scale RNA Production System (Promega). Recombined 3D ${ }^{\mathrm{pol}}$ and ssRNA template were first mixed in $4 \mu \mathrm{L}$ of initiation buffer containing $10 \mu \mathrm{M} 3 \mathrm{D}^{\text {pol }} \mathrm{RNA}, 0.4 \mu \mathrm{M}$ RNA templates, $500 \mu \mathrm{M}$ normal r-A/U/G-TP (Applied Biosystem), $50 \mathrm{mM} \mathrm{NaCl}$ (Thermo Fisher), $1.5 \mathrm{mM} \mathrm{MgCl}_{2}$ (Fisher), $4 \mathrm{mM}$ TCEP (Pierce TCEP-HCl, Life Technologies), 50 mM HEPES (pH 6.5, Invitrogen), and 1 unit/ $\mu$ L RiboLock RNase inhibitor (Life Technologies). Normal r-CTP $(500 \mu \mathrm{M})$ was added in the positive control, whereas no r-CTP or $\mathrm{dFdC}$-TP was added in the negative control. Designated amounts of r-CTP and/or dFdCTP were added in the experimental groups. The mixture was incubated at room temperature 
for $15 \mathrm{~min}$ to form elongation complex. Following that, the elongation complex was locked by adding $16 \mu \mathrm{L}$ of elongation buffer containing $356 \mathrm{mM} \mathrm{NaCl}, 200 \mu \mathrm{M} \mathrm{r}-\mathrm{A} / \mathrm{U} / \mathrm{G}-\mathrm{TP}, 1.5$ $\mathrm{mM} \mathrm{MgCl}_{2}, 4 \mathrm{mM}$ TCEP, and $50 \mathrm{mM}$ HEPES (pH 6.5). The mixtures were then incubated at room temperature for another $2 \mathrm{~h}$. After incubation, the reaction was quenched by mixing with $16 \mathrm{mM}$ EDTA, and the RNA products were extracted using a phenol/chloroform/ isoamyl alcohol solution (Sigma). To extract the RNA, 1 volume sample was first mixed with 1 volume of phenol/chloroform/isoamyl alcohol (125:24:1, $\mathrm{pH} 4.5$ ), vortexed for $1 \mathrm{~min}$, and spun at 13,000 rpm for $2 \mathrm{~min}$. The upper, aqueous phase was transferred to a fresh tube and mixed with 1 volume of chloroform/isoamyl alcohol (24:1), vortexed for $1 \mathrm{~min}$, and centrifuged at 13,000 rpm for $2 \mathrm{~min}$. The upper, aqueous phase was then transferred to a new tube and mixed with 0.1 volume of $3 \mathrm{M}$ sodium acetate ( $\mathrm{pH}$ 5.2, Life Technologies) and 1 volume of isopropanol. The mixture was placed on ice for $15 \mathrm{~min}$ and centrifuged for 10 min. The supernatant was carefully removed, and the pellet was washed once with $1 \mathrm{~mL}$ of $70 \%$ ethanol. The pellet was air-dried and dissolved in $\mathrm{ddH}_{2} \mathrm{O}$. The RNA products were then examined by gel electrophoresis and stained by ethidium bromide.

\section{Supplementary Material}

Refer to Web version on PubMed Central for supplementary material.

\section{Acknowledgments}

We thank Dr. Peersen from Colorado State University for kindly providing the recombined poliovirus RNAdependent RNA polymerase. This research was supported in part by U.S. National Institutes of Health Grant R01OD015092, HL064560, and HL129887, and Contract HHSN266200500016-I, Task Orders D23 and C28.

\section{References}

1. Nathanson N, Kew OM. From emergence to eradication: the epidemiology of poliomyelitis deconstructed. Am J Epidemiol. 2010; 172:1213-1229.

2. Jenkins HE, Aylward RB, Gasasira A, Donnelly CA, Mwanza M, et al. Implications of a Circulating Vaccine-Derived Poliovirus in Nigeria. N Engl J Med. 2010; 362:2360-2369.

3. Shimizu H, Thorley B, Paladin FJ, Brussen KA, Stambos V, et al. Circulation of type 1 vaccinederived poliovirus in the Philippines in 2001. J Virol. 2004; 78:13512-13521.

4. Watson KG, Brown RN, Cameron R, Chalmers DK, Hamilton S, Jin B, Krippner GY, Luttick A, McConnell DB, Reece PA, Ryan J, Stanislawski PC, Tucker SP, Wu WY, Barnard DL, Sidwell RW. An Orally Bioavailable Oxime Ether Capsid Binder with Potent Activity against Human Rhinovirus. J Med Chem. 2003; 46:3181-3184.

5. Yang CF, Naguib T, Yang SJ, Nasr E, Jorba J, et al. Circulation of Endemic Type 2 Vaccine-Derived Poliovirus in Egypt from 1983 to 1993. J Virol. 2003; 77:8366-8377.

6. Duintjer Tebbens RJ, Pallansch MA, Cochi SL, Wassilak SG, Thompson KM. An economic analysis of poliovirus risk management policy options for 2013-2052. BMC Infect Dis. 2015; 15:389.

7. Duintjer Tebbens RJ, Pallansch MA, Thompson KM. Modeling the prevalence of immunodeficiency-associated long-term vaccine-derived poliovirus excretors and the potential benefits of antiviral drugs. BMC Infect Dis. 2015; 15:379.

8. U.S. National Research Council. Exploring the Role of Antiviral Drugs in the Eradication of Polio: Workshop Report. National Academies Press; Washington, DC, USA: 2006.

9. Pevear DC, Tull TM, Seipel ME, Groarke JM. Activity of Pleconaril against Enteroviruses. Antimicrob Agents Chemother. 1999; 43:2109-2115.

10. Collett MS, Neyts J, Modlin JF. A case for developing antiviral drugs against polio. Antiviral Res. 2008; 79:179-187. 
11. Oberste MS, Moore D, Anderson B, Pallansch MA, Pevear DC, Collett MS. In Vitro Antiviral Activity of V-073 against Polioviruses. Antimicrob Agents Chemother. 2009; 53:4501-4503.

12. Brown RN, Cameron DK, Chalmers S, Hamilton S, Luttick A, Krippner GY, McConnell DB, Nearn R, Stanislawski PC, Tucker SP, Watson KG. 2-Ethoxybenzoxazole as a bioisosteric replacement of an ethyl benzoate group in a human rhinovirus (JRV) capsid binder. Biorg Med Chem Lett. 2005; 15:2051-2055.

13. Crotty S, Cameron C, Andino R. RNA virus error catastrophe: direct molecular test by using ribavirin. Proc Natl Acad Sci U S A. 2001; 98:6895-6900.

14. Crotty S, Maag D, Arnold JJ, Zhong W, Lau JYN, Hong Z, Andino R, Cameron CE. The broadspectrum antiviral ribonucleoside ribavirin is an RNA virus mutagen. Nat Med. 2000; 6:13751379. [PubMed: 11100123]

15. Gazina E, Smidansky E, Holien J, Harrison D, et al. Amiloride is a competitive inhibitor of coxsackievirus B3 RNA polymerase. J Virol. 2011; 85:10364-10374. [PubMed: 21795353]

16. van der Linden L, Vives-Adrian L, Selisko B, Ferrer-Orta C, Liu X, et al. The RNA Template Channel of the RNA-Dependent RNA Polymerase as a Target for Development of Antiviral Therapy of Multiple Genera within a Virus Family. PLoS Pathog. 2015; 11:e1004733.

17. van der Linden L, Wolthers K, van Kuppeveld F. Replication and Inhibitors of Enteroviruses and Parechoviruses. Viruses. 2015; 7:4529-4562. [PubMed: 26266417]

18. Bryksin AV, Matsumura I. Overlap extension PCR cloning: a simple and reliable way to create recombinant plasmids. BioTechniques. 2010; 48:463-465. [PubMed: 20569222]

19. Bouchard MJ, Lam DH, Racaniello VR. Determinants of attenuation and temperature sensitivity in the type 1 poliovirus Sabin vaccine. J Virol. 1995; 69:4972-4978.

20. Pfister T, Wimmer E. Characterization of the Nucleoside Triphosphatase Activity of Poliovirus Protein 2C Reveals a Mechanism by Which Guanidine Inhibits Poliovirus Replication. J Biol Chem. 1999; 274:6992-7001.

21. Beumer J, Eiseman J, Parise R, Joseph E, Covey J, Egorin M. Modulation of gemcitabine ( $2^{\prime}, 2^{\prime}$ difluoro- $2^{\prime}$-deoxycytidine) pharmacokinetics, metabolism, and bioavailability in mice by $3,4,5,6$ tetrahydrouridine. Clin Cancer Res. 2008; 14:3529-3535.

22. Veltkamp S, Pluim D, van Eijndhoven M, Bolijn M, Ong F, Govindarajan R. New insights into the pharmacology and cytotoxicity of gemcitabine and $2^{\prime}, 2^{\prime}$-difluorodeoxyuridine. Mol Cancer Ther. 2008; 7:2415-2425. [PubMed: 18723487]

23. Hobdey SE, Kempf BJ, Steil BP, Barton DJ, Peersen OB. Poliovirus Polymerase Residue 5 Plays a Critical Role in Elongation Complex Stability. J Virol. 2010; 84:8072-8084.

24. Gong P, Peersen OB. Structural basis for active site closure by the poliovirus RNA-dependent RNA polymerase. Proc Natl Acad Sci U S A. 2010; 107:22505-22510.

25. Shu B, Gong P. Structural basis of viral RNA-dependent RNA polymerase catalysis and translocation. Proc Natl Acad Sci U S A. 2016; 113:E4005-E4014.

26. Mesmin B, Bigay J, Moser von Filseck J, Lacas-Gervais S, Drin G, Antonny B. A Four-Step Cycle Driven by PI(4)P Hydrolysis Directs Sterol/PI(4)P Exchange by the ER-Golgi Tether OSBP. Cell. 2013; 155:830-843. [PubMed: 24209621]

27. Strating JRPM, van der Linden L, Albulescu L, Bigay J, Arita M, Delang L, Leyssen P, van der Schaar HM, Lanke KHW, Thibaut HJ, Ulferts R, Drin G, Schlinck N, Wubbolts RW, Sever N, Head SA, Liu JO, Beachy PA, De Matteis MA, Shair MD, Olkkonen VM, Neyts J, van Kuppeveld FJM. Itraconazole Inhibits Enterovirus Replication by Targeting the Oxysterol-Binding Protein. Cell Rep. 2015; 10:600-615.

28. Meneghesso S, Vanderlinden E, Stevaert A, McGuigan C, Balzarini J, Naesens L. Synthesis and biological evaluation of pyrimidine nucleoside monophosphate prodrugs targeted against influenza virus. Antiviral Res. 2012; 94:35-43.

29. Chen CY, Huang D, Wang R, Zhang M, Xu J, Qian L, Zhu Y, Zhang AZ, Yang E, Qaqish A, Chumakov K, Kouiavskaia D, Vignuzzi M, Nathanson N, Macadam A, Andino R, Kew O, Shen L, Chen Z. A Nonhuman Primate Model of Oral Poliovirus Infection Leading to Paralytic Poliomyelitis. ACS Infec Dis. 2016 
30. Kang H, Kim C, Kim D-E, Song JH, Choi M, Choi K, Kang M, Lee K, Kim HS, Shin JS, Kim J, Han SB, Lee MY, Lee SU, Lee CK, Kim M, Ko HJ, van Kuppeveld FJM, Cho S. Synergistic antiviral activity of gemcitabine and ribavirin against enteroviruses. Antiviral Res. 2015; 124:1-10.

31. Ferrer-Orta C, Arias A, Escarmís C, Verdaguer N. A comparison of viral RNA-dependent RNA polymerases. Curr Opin Struct Biol. 2006; 16:27-34.

32. Ng KKS, Arnold JJ, Cameron CE. Structure-Function Relationships Among RNA-Dependent RNA Polymerases. Curr Top Microbiol Immunol. 2008; 320:137-156.

33. Campagnola G, McDonald S, Beaucourt S, Vignuzzi M, Peersen OB. Structure-Function Relationships Underlying the Replication Fidelity of Viral RNA-Dependent RNA Polymerases. J Virol. 2015; 89:275-286.

34. Crouch SP, Kozlowski R, Slater KJ, Fletcher J. The use of ATP bioluminescence as a measure of cell proliferation and cytotoxicity. J Immunol Methods. 1993; 160:81-88. [PubMed: 7680699]

35. Gohara DW, Ha CS, Kumar S, Ghosh B, Arnold JJ, Wisniewski TJ, Cameron CE. Production of "Authentic" Poliovirus RNA-Dependent RNA Polymerase (3Dpol) by Ubiquitin-ProteaseMediated Cleavage in Escherichia coli. Protein Expression Purif. 1999; 17:128-138.

36. Thompson AA, Peersen OB. Structural basis for proteolysis-dependent activation of the poliovirus RNA-dependent RNA polymerase. EMBO J. 2004; 23:3462-3471. 
a.

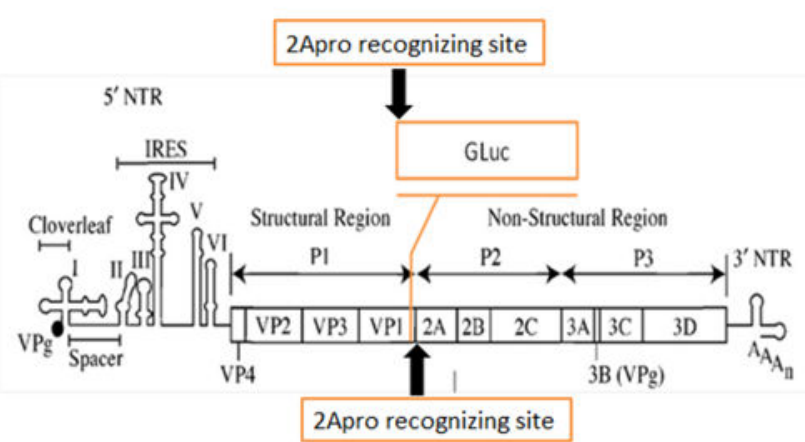

c.

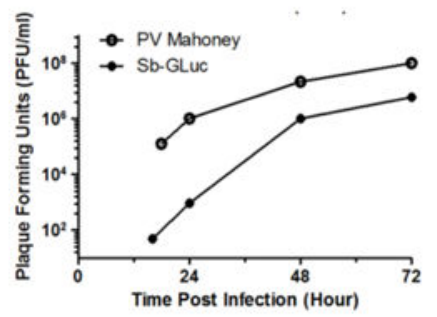

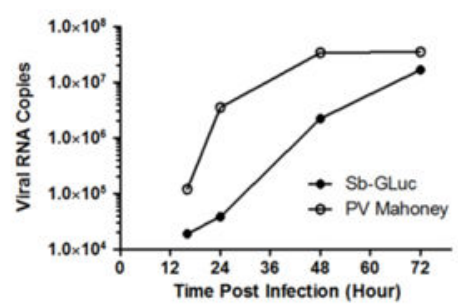

b.

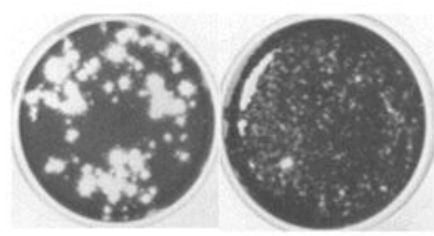

e.

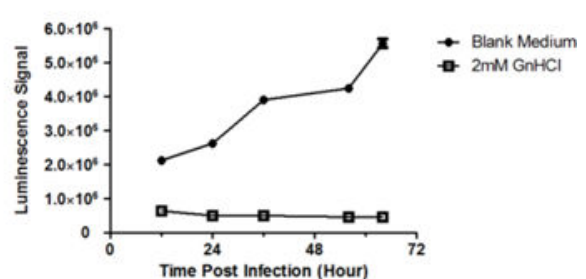

Figure 1.

Generate and define recombinant poliovirus expressing Luciferase (Sb-GLuc): (a) Gaussia Luciferase $(G L u c)$ reporter gene was introduced into the poliovirus genome at the end of the VP1 gene. (b) Representative pictures of the plaque assay results using Sb-GLuc particles (right) and WT-PV (left) after $72 \mathrm{~h}$ of incubation. (c) Plaque-forming units (PFUs) of SbGLuc and WT-PV. HeLa cells were infected by Sb-GLuc or WT-PV, the viral particles were harvested after 16, 24, 48, and $72 \mathrm{~h}$ of incubation by centrifuge, and the viral PFUs were examined by plaque assays. (d) Viral RNA copy numbers of Sb-GLuc and WT-PV. HeLa cells were infected by Sb-GLuc or WT-PV, the viral particles were harvested after 16, 24, 48 , and $72 \mathrm{~h}$ of incubation by centrifuge, and the viral RNA copy numbers were examined by qRT-PCR. (e) Luminescent signal curves of Sb-GLuc incubated with or without the presence of $2 \mathrm{mM} \mathrm{GnHCl}$. Luminescent signals were assessed after 12, 24, 36, 56, and $64 \mathrm{~h}$ of incubation. 
a.

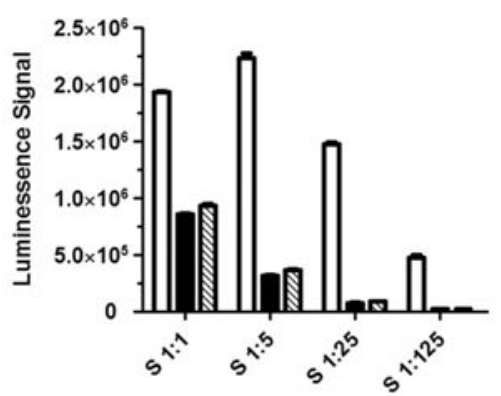

b.

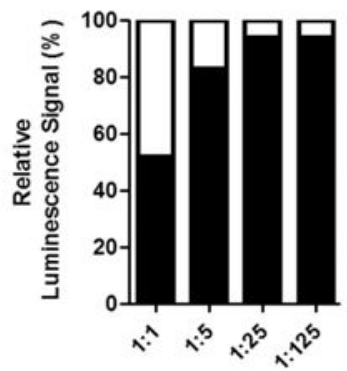

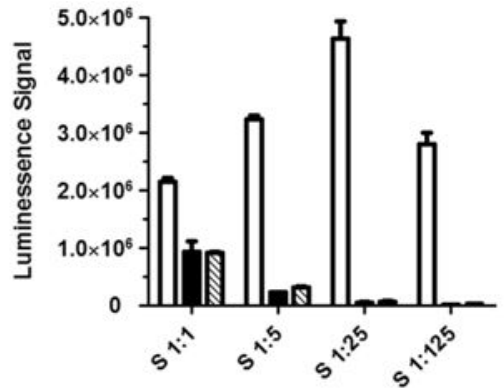

Blank Medium $2 \mathrm{mM} \mathrm{GnHCl}$

Backgroud

Figure 2.

Validate and optimize the High-throughput intracellular screening assay: (a) Luminescent signals at $24 \mathrm{~h}$ post infection (left) and $48 \mathrm{~h}$ post infection (right); $5 \times 10^{4} \mathrm{HeLa}$ cells were infected by $4 \times 10^{4} \mathrm{PFU}(1: 1), 8 \times 10^{3} \mathrm{PFU}(1: 5), 1.6 \times 10^{3} \mathrm{PFU}(1: 25)$, or $3.2 \times 10^{2} \mathrm{PFU}$ (1:125) Sb-GLuc. The white bar represents Sb-GLuc incubated without treatment, the black bar represents Sb-GLuc incubated in the presence of $2 \mathrm{mM} \mathrm{GnHCl}$, and the gray bar represents Sb-GLuc incubated without HeLa cells to measure the luminescent signals in the background. (b) Percentage of background in total luminescent signals at $24 \mathrm{~h}$ post infection (left) and $48 \mathrm{~h}$ post infection. The white bar shows the net luminescent signals, whereas the black bar represents the background. 
a.

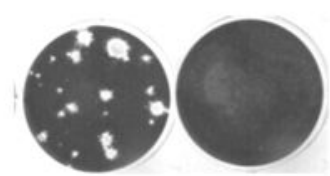

b.

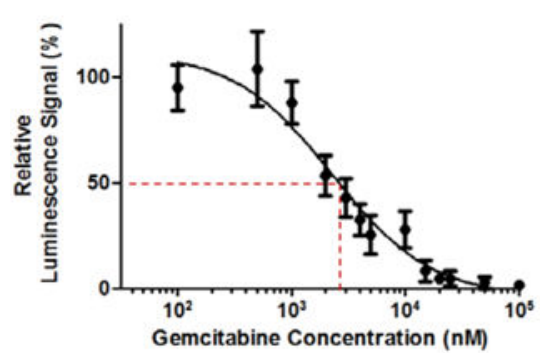

e.

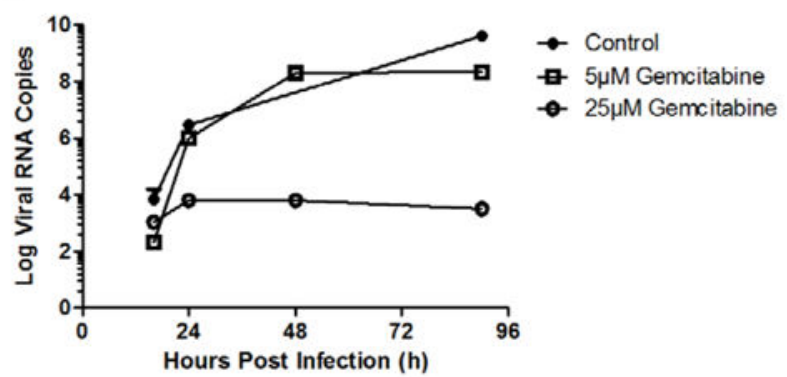

c.

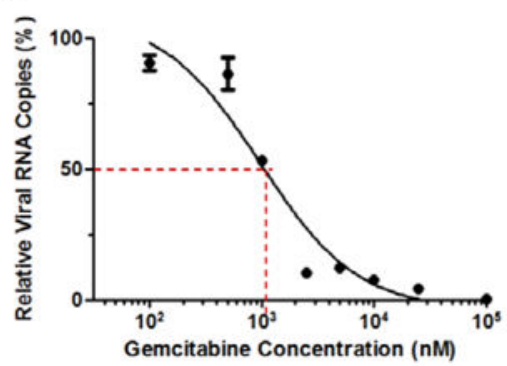

f. d.

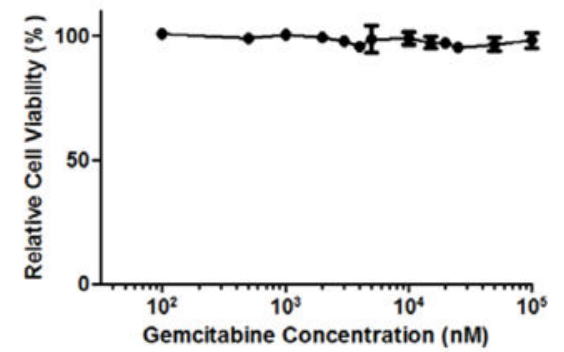

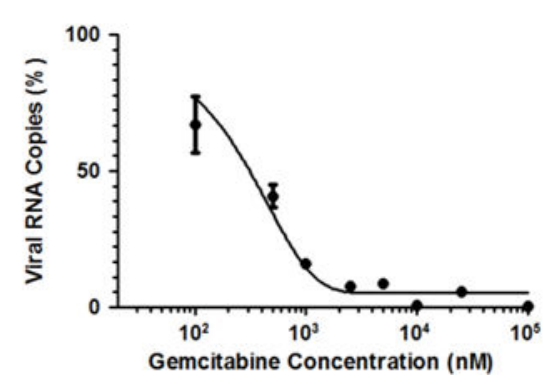

Figure 3.

Verify and characterize Gemcitabine for the ability to inhibit poliovirus replication: (a) Representative plaque assay results using WT-PV incubated in the presence of $25 \mu \mathrm{M}$ gemcitabine (left) or in the absence of gemcitabine (right) for $48 \mathrm{~h} ; 10^{6} \mathrm{HeLa}$ cells were infected by $2 \times 10^{5}$ PFU WT-PV (MOI $=0.2$ ) and incubated for 2 days. Data are representative of multiple repeated experiments. More data are shown in Supporting Information Figure S3. (b) Luminescent signals of Sb-GLuc incubated in the presence of various concentrations of gemcitabine for $48 \mathrm{~h} ; 4 \times 10^{5} \mathrm{HeLa}$ cells were incubated with $10^{5}$ WT-PV (MOI $=0.25$ ). The $\mathrm{IC}_{50}$ of gemcitabine against Sb-GLuc was calculated as $2.5 \mu \mathrm{M}$. (c) Viral RNA copy numbers of Sb-GLuc $(\mathrm{MOI}=0.25)$ incubated in the presence of various concentrations of gemcitabine for $48 \mathrm{~h}$, measured by qRT-PCR. The $\mathrm{IC}_{50}$ of gemcitabine against Sb-GLuc was calculated as $1 \mu \mathrm{M}$. (d) Cell viability of HeLa cells incubated in the presence of various concentrations of gemcitabine without viral infection for $48 \mathrm{~h}$, measured by intracellular ATP levels. (e) Viral RNA copy numbers of WT-PV incubated in the presence of 0,5 , and $25 \mu \mathrm{M}$ gemcitabine for $48 \mathrm{~h} ; 4 \times 10^{5} \mathrm{HeLa}$ cells were infected by 100 PFU WT-PV, and gemcitabine was added every $24 \mathrm{~h}$ during the incubation. (f) Viral RNA copy numbers of WT-PV incubated in the presence of various concentrations of gemcitabine for $48 \mathrm{~h} ; 4 \times 10^{5} \mathrm{HeLa}$ cells were infected by $100 \mathrm{PFU}$ WT-PV, and gemcitabine was added every $24 \mathrm{~h}$ during the incubation. Viral RNA copy numbers were determined by qRT-PCR. 


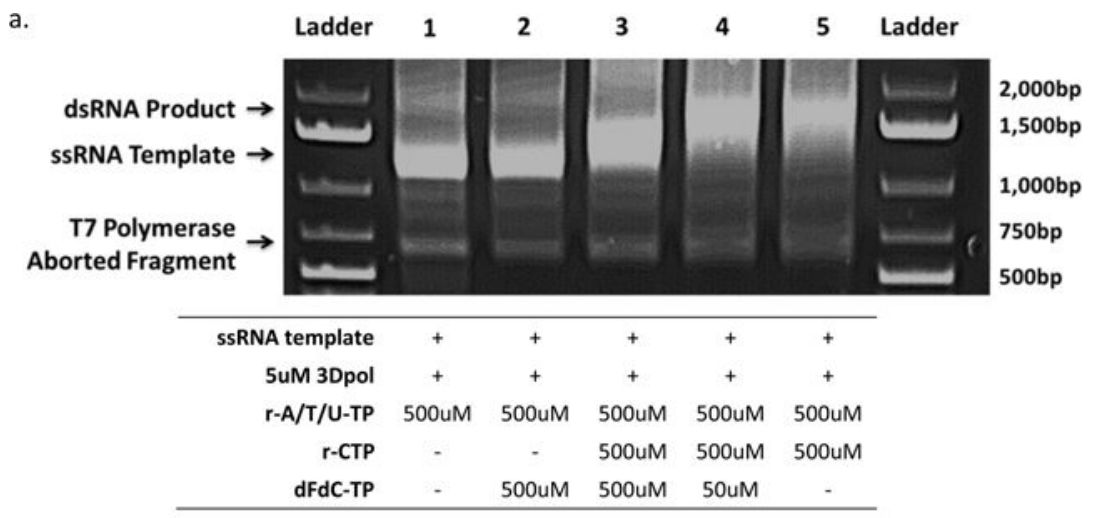

b.

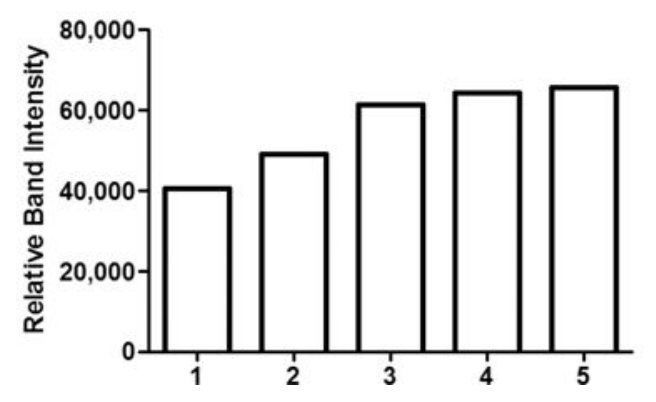

Figure 4.

Gemcitabine metabolite dFdC-TP inhibits the ability of PV RNA polymerase (3Dpol) to synthesize PV dsRNA: (a) $10 \mu \mathrm{M}$ recombined $3 \mathrm{D}^{\text {pol }}$ was incubated with $0.4 \mu \mathrm{M}$ linear ssRNA fragment of PV (lower band) with or without dFdC-TP for $2 \mathrm{~h}$, and the production of dsRNA (upper band) was analyzed using electrophoresis and stained by EB. Lane 1 is the negative control in which $500 \mu \mathrm{M}$ r-A,U,G-TP was added in the absence of r-CTP or dFdC. Lane 5 is the positive control in which $500 \mu \mathrm{M}$ of all four r-NTPs was added; $500 \mu \mathrm{M} \mathrm{dFdC-}$ TP was added in addition to $500 \mu \mathrm{M} \mathrm{r}-\mathrm{A}, \mathrm{U}, \mathrm{G}-\mathrm{TP}$ in lane $2 ; 500 \mu \mathrm{M} \mathrm{dFdC-TP}$ and $500 \mu \mathrm{M} \mathrm{r}-$ CTP were added in addition to $500 \mu \mathrm{M} \mathrm{r}-\mathrm{A}, \mathrm{U}, \mathrm{G}-\mathrm{TP}$ in lane 3; $50 \mu \mathrm{M} \mathrm{dFdC-TP}$ and $500 \mu \mathrm{M}$ r-CTP were added in addition to $500 \mu \mathrm{M}$ r-A,U,G-TP in lane 4. (b) Intensity of the bands. 


\section{Table 1}

Compounds Identified from the High-Throughput Screening Assay

\begin{tabular}{llll}
\hline index & $\boldsymbol{E}_{\mathbf{c}}(\boldsymbol{\%})$ & $\boldsymbol{V}_{\mathbf{c}}(\boldsymbol{\%})$ & compound name \\
\hline 2B16 & 96.0 & 79.4 & itraconazole \\
2J05 & 92.8 & 87.9 & thiostrepton \\
2K14 & 82.1 & 81.5 & meclocycline sulfosalicylate \\
2M19 & 83.0 & 103.1 & ketoconazole \\
3A05 & 80.4 & 80.1 & gefitinib \\
3F21 & 82.80 & 88.4 & ethaverine hydrochloride \\
3G18 & 81.9 & 88.8 & ribostamycin sulfate salt \\
4G10 & 85.1 & 75.4 & cyproterone acetate \\
4G17 & 81.8 & 92.0 & zuclopenthixol hydrochloride \\
4I07 & 94.1 & 91.2 & azapropazone \\
4N07 & 96.6 & 87.9 & gemcitabine
\end{tabular}

